BMJ Open

Sport \&

Exercise

Medicine

\title{
Changes in lung function during exercise are independently mediated by increases in deep body temperature
}

\author{
Michael J Tipton, ${ }^{1}$ Pippa Kadinopoulos, ${ }^{2}$ Dan Roiz de Sa, ${ }^{1,3}$ Martin J Barwood ${ }^{4}$
}

To cite: Tipton MJ, Kadinopoulos P, Sa DR, et al. Changes in lung function during exercise are independently mediated by increases in deep body temperature. BMJ Open Sport Exerc Med 2017;3 e000210. doi:10.1136/ bmjsem-2016-000210

Accepted 28 February 2017

\section{CrossMark}

\section{${ }^{1}$ Department of Sport and Exercise Science, Extreme Environments Laboratory (EEL), University of Portsmouth, Portsmouth, UK ${ }^{2}$ HMS Nelson, HM Naval Base Portsmouth, Portsmouth, UK ${ }^{3}$ Environmental Medicine \& Science Unit, Institute of Naval Medicine, Gosport, UK ${ }^{4}$ Department of Sport, Health and Nutrition, Leeds Trinity University, Leeds, UK}

Correspondence to Michael J Tipton; michael. tipton@port.ac.uk

\section{ABSTRACT \\ Background This study examined whether an increase in deep body temperature contributes to increases in ventilatory flow indicative of bronchodilatation.}

Method The study employed a within-participant repeated measures design. Nine participants (mean (SD): age 22 (3) years; height 177.7 (8.3) cm; mass $80.2(19.1) \mathrm{kg})$ completed three conditions: exercise (EXERC; $30 \mathrm{~min}$ ); $40^{\circ} \mathrm{C}$ water immersion (IMM40; $30 \mathrm{~min})$ to passively raise rectal temperature $\left(T_{\text {re }}\right)$ and $35^{\circ} \mathrm{C}$ immersion (IMM35; $30 \mathrm{~min}$ ) asa thermoneutral control for IMM40. A forced vital capacity (FVC) manoeuvre was performed at the start of the test and every $10 \mathrm{~min}$ thereafter. Forced expiratory volume in 1 $\mathrm{s}\left(\mathrm{FEV}_{1}\right), \mathrm{FEV}_{1} / \mathrm{FVC}, 25 \%, 50 \%$ and $75 \%$ maximal expiratory flow during FVC (forced expiratory flow (FEF)25, FEF50, FEF75) were also measured. Data were compared using a repeated measures two-way analysis of variance, with a $0.05 \alpha$ level.

Results Rectal temperature ( $\left.\mathrm{T}_{\mathrm{re}}\right)$ peaked after $30 \mathrm{~min}$ in the EXERC (mean (SD) $38.0(0.3)^{\circ} \mathrm{C}$ ) and IMM40 $\left(38.2(0.2)^{\circ} \mathrm{C}\right)$ conditions and both were higher $(p<0.05)$ than at the corresponding time in the thermoneutral condition $\left(37.2(0.2)^{\circ} \mathrm{C}\right)$. At this time, $\mathrm{FEV}_{1}$ was $4.5(0.6), 4.6(0.3)$ and $4.4(0.6) \mathrm{L}$, respectively. $\mathrm{T}_{\mathrm{re}}, \mathrm{FEV}_{1}$ and $\mathrm{FEV}_{1} / \mathrm{FVC}$ were greater in the IMM40 and EXERC conditions compared with the IMM35 condition. Interaction effects were evident for FEF50 and FEF75 $(p<0.05)$, being higher in IMM40 and EXERC conditions.

Conclusion Increasing deep body temperature, independently, contributes to the increased airflow ascribed to bronchodilatation when exercising.

\section{INTRODUCTION}

In healthy individuals, exercise produces either a mild bronchodilatation, facilitating an increase in airflow without a significant increase in airway resistance and the work of breathing, ${ }^{1}$ or has no effect. ${ }^{2}$ In healthy individuals and patients with asthma, druginduced bronchoconstriction is reversed by exercise. ${ }^{3}$ The suggested mechanisms for this include: parasympathetic/sympathetic balance $^{4}$; endogenous catecholamines ${ }^{5-8}$; prostaglandin $\mathrm{E}_{2}$ release from mast cells and airway epithelial cells $^{4}{ }^{9}$; deep inspirations

\section{What are the new findings?}

This study demonstrates, for the first time, that body temperature, independently of exercise, changes lung function in a very similar way to that seen with exercise.

- These original lung function data address a largely ignored factor that has significant implications for the experimental design and interpretation of studies investigating the impact of exercise, as well as other interventions that raise body temperature.

and mechanical stretching of the airway walls and a reflex inhibition of bronchomotor tone via slowly adapting pulmonary stretch receptors; mechanical and length-tension effects on airway smooth muscle. ${ }^{10-13}$

One factor that has been largely overlooked is body temperature. While it has been established that cooling and heating skeletal muscle and connective tissue change their physical and physiological properties and function, ${ }^{14}{ }^{15}$ little is known about the effect of the increase in body temperature associated with exercise on the respiratory tissues and lung function. Suman et al ${ }^{16}$ suggested that within a population with asthma the increase in deep body temperature $\left(\mathrm{T}_{\mathrm{db}}\right)$ that occurs as a result of exercising for over $20 \mathrm{~min}$ has a negative effect on airway patency. The study showed a bronchodilatory response up to $15 \mathrm{~min}$ of exercise, thereafter a significant bronchoconstriction. They hypothesised that the increase in temperature caused bronchial vasodilatation resulting in engorged blood vessels and/or an increase in the permeability of the endothelium, resulting in airway obstruction. $\mathrm{T}_{\mathrm{db}}$ was not measured in the study. Suman et $a l^{12}$ examined isocapnic ventilation and exercise in a population with asthma. They suggested that an increase in oesophageal temperature may aggravate the already hyperactive airways by increasing airway mucosal blood 
$\leadsto-$ Tre EXERCISE $\quad \diamond$ Tre IMM $40 \quad \square$-Tre IMM 35

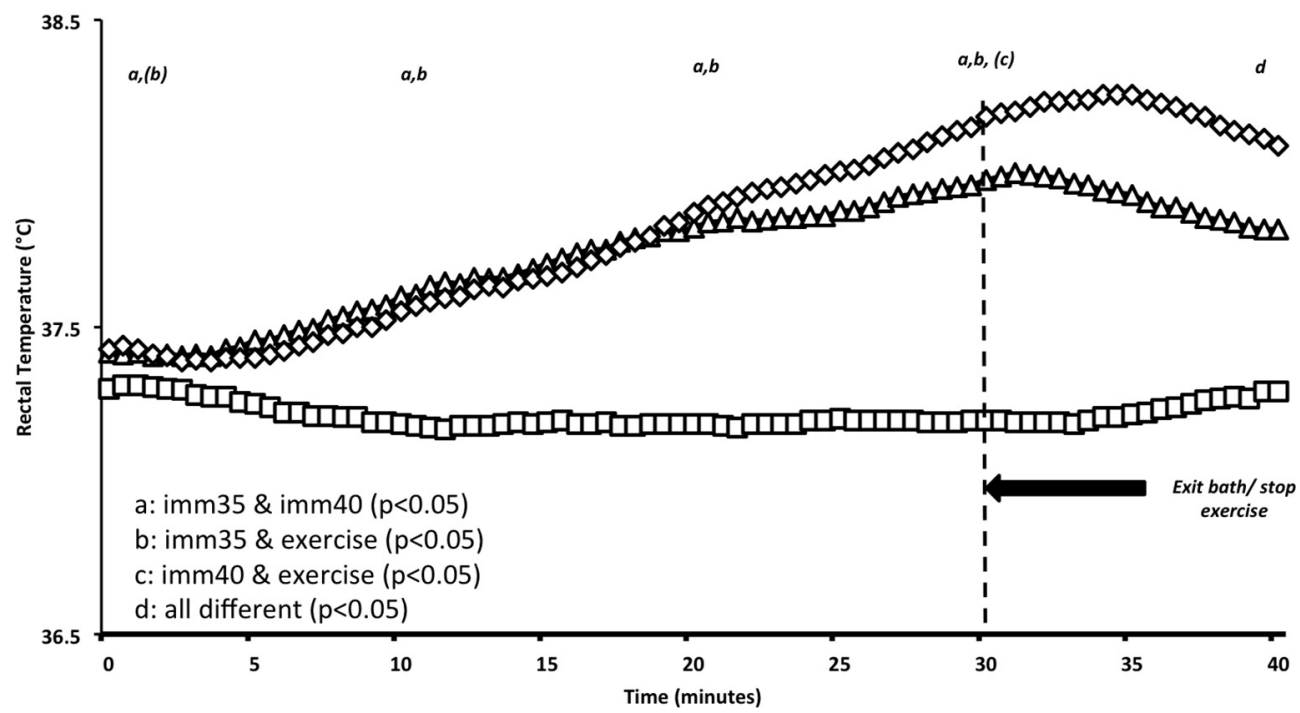

Figure 1 Mean rectal temperature $\left({ }^{\circ} \mathrm{C}\right)$ data for each condition over the experimental period. Conditions and significant differences as marked $0=p<0.1$ in this comparison $(n=9)$. $T_{\text {re }}$ EXERCISE, rectal temperature during clothed exercise for 30 minutes; $\mathrm{T}_{\text {re }} \mathrm{IMM} 35$, rectal temperature during $35^{\circ} \mathrm{C}$ water immersion; $\mathrm{T}_{\text {re }} \mathrm{IMM} 40$, rectal temperature during $40^{\circ} \mathrm{C}$ water immersion.

flow. The increase in warm blood may also cause vascular oedema and congestion, resulting in airway obstruction.

Choukroun et $a l^{17}$ reported that immersion in cold water compared with thermoneutral water produced a significant reduction $(-3 \%, \mathrm{p}<0.05)$ in vital capacity (VC). Between thermoneutral water and hot water there was a significant increase $(+3 \%$, $\mathrm{p}<0.05)$ in VC. It was suggested that the increase in ventilation was due to modifications in respiratory muscle functioning (possibly hyperventilation) due to the increased deep body temperature. Hyperthermia- induced hyperventilation has also been reported by Hayashi et $a l,{ }^{18}$ who reported an increase in minute ventilation when immersed in $35^{\circ} \mathrm{C}$ and $45^{\circ} \mathrm{C}$ water compared with $10^{\circ} \mathrm{C}$ water. In contrast, Martin et al $l^{19}$ reported that warm water heating failed to change ventilation levels.

The measurement of airway resistance is technically difficult during exercise, ${ }^{20}$ and neither airway diameter nor smooth muscle activation can be measured in exercising humans; spirometry is therefore used to indicate changes in these values. The most widely used

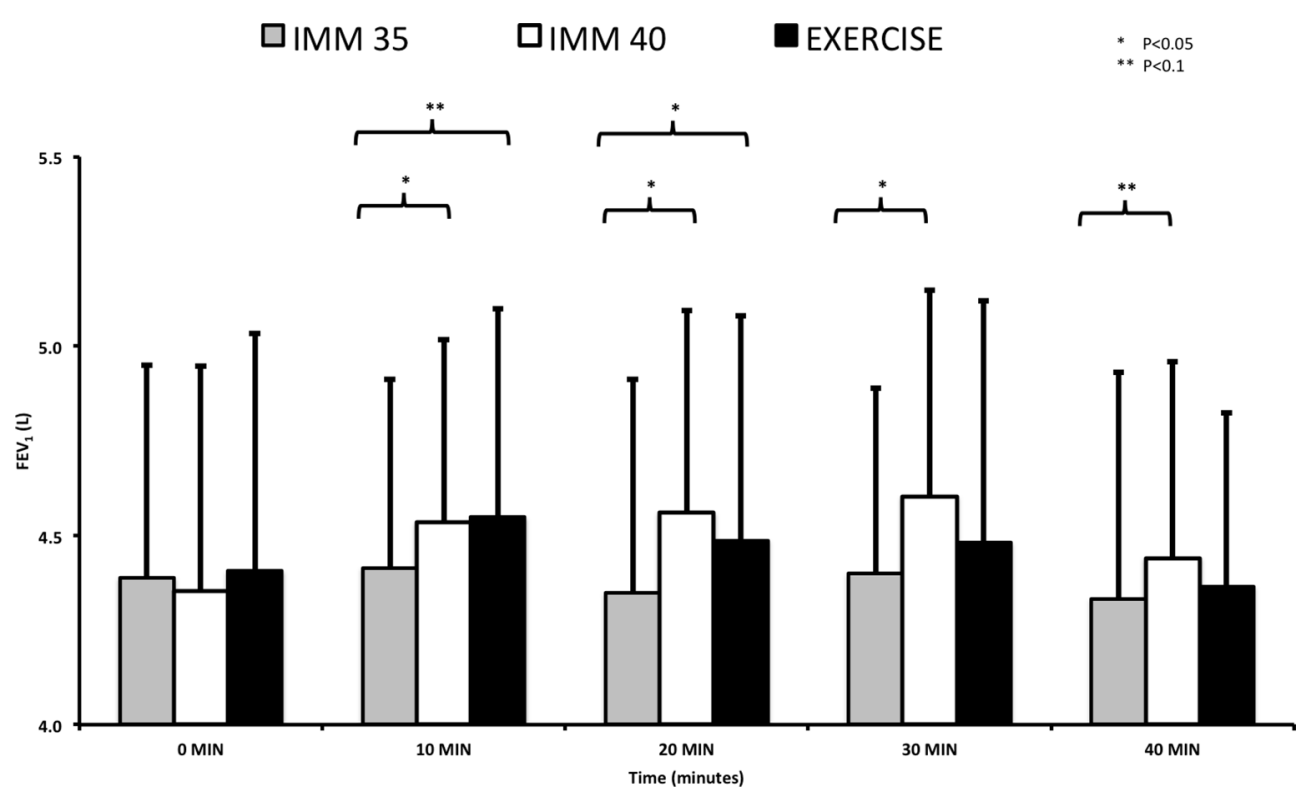

Figure 2 Mean (SD) FEV 1 (L) data for each condition over the experimental period. Conditions and significant differences as marked $(n=9)$. $\mathrm{FEV}_{1}$, forced expiratory volume in 1s. ; IMM35, $35^{\circ} \mathrm{C}$ water immersion; IMM40, $40^{\circ} \mathrm{C}$ water immersion; EXERCISE, clothed exercise for 30 minutes 


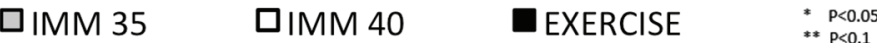

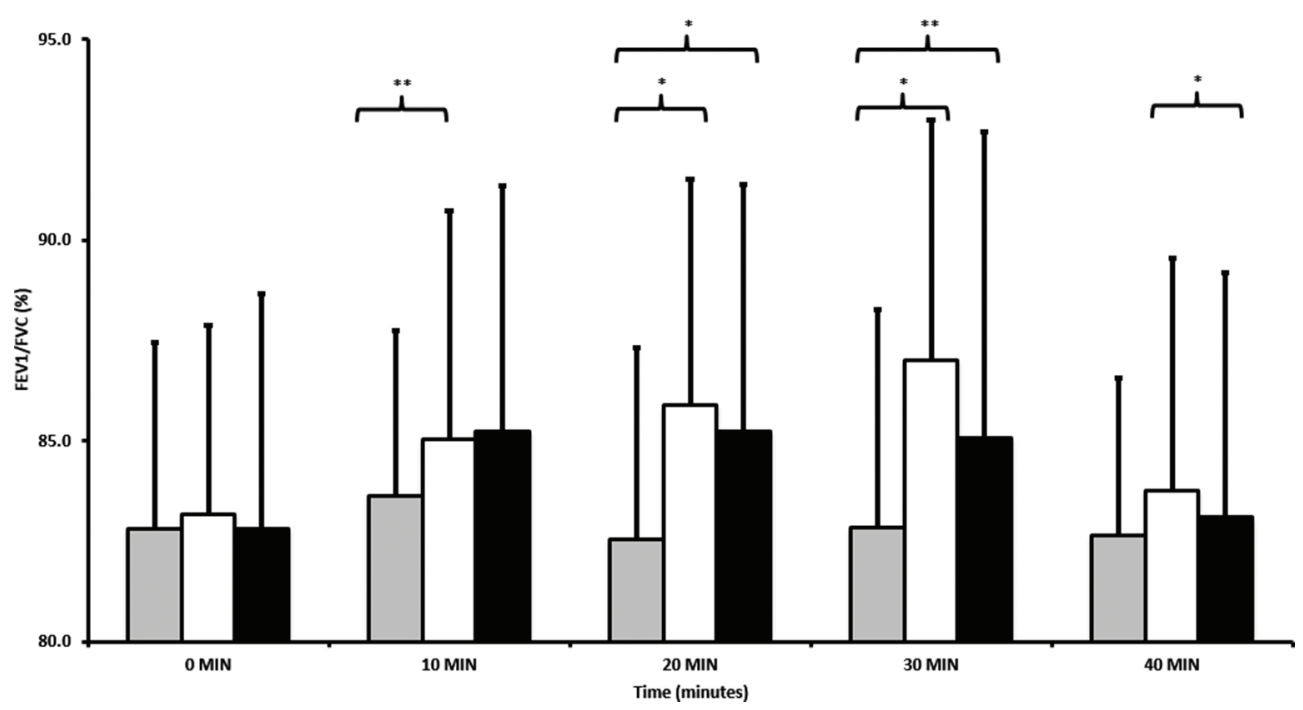

Figure 3 Mean (SD) FEV 1 /FVC (\%) data for each condition over the experimental period. Conditions and significant differences as marked $(n=9)$. $\mathrm{FEV}_{1}$, forced expiratory volume in $1 \mathrm{~s}$; $\mathrm{FVC}$, forced vital capacity; IMM $35,35^{\circ} \mathrm{C}$ water immersion; IMM40, $40^{\circ} \mathrm{C}$ water immersion; EXERCISE, clothed exercise for 30 minutes.

pulmonary function test for the diagnosis and indication of severity of lung disease is spirometry. This provides a measurement of VC, forced vital capacity (FVC), forced expiratory volume (FEV), FEV in $1 \mathrm{~s}$ $\left(\mathrm{FEV}_{1}\right)$ or as a forced expiratory flow (FEF). The measures of flow indirectly depend on the resistance to air being expired. ${ }^{21}$ When healthy, most airway resistance occurs in fourth-generation to eighth-generation airways, and therefore $\mathrm{FEV}_{1}$ largely reflects large airway obstruction ${ }^{22}$ but gives little information on airflow in the smaller airways unless there is significant obstructive lung disease. Partitioning the FVC curve into components helps identify the areas of dysfunction within the respiratory tract. FEF can be measured at various percentages of expired gas flow and is represented as FEF25 (FEF where 25\% of FVC has been expired), FEF50 and FEF75. The FEF25-75 per cent represents the forced mid-expiratory flow over the middle $50 \%$ of the FVC curve; it reflects airflow in the distal airways and is considered to be effort independent. ${ }^{23}$ However it is dependent on the FVC, and changes to FVC will necessarily affect the portion of the flow volume curve examined. ${ }^{22}$ In clinical measurements of airway obstruction, especially in the smaller
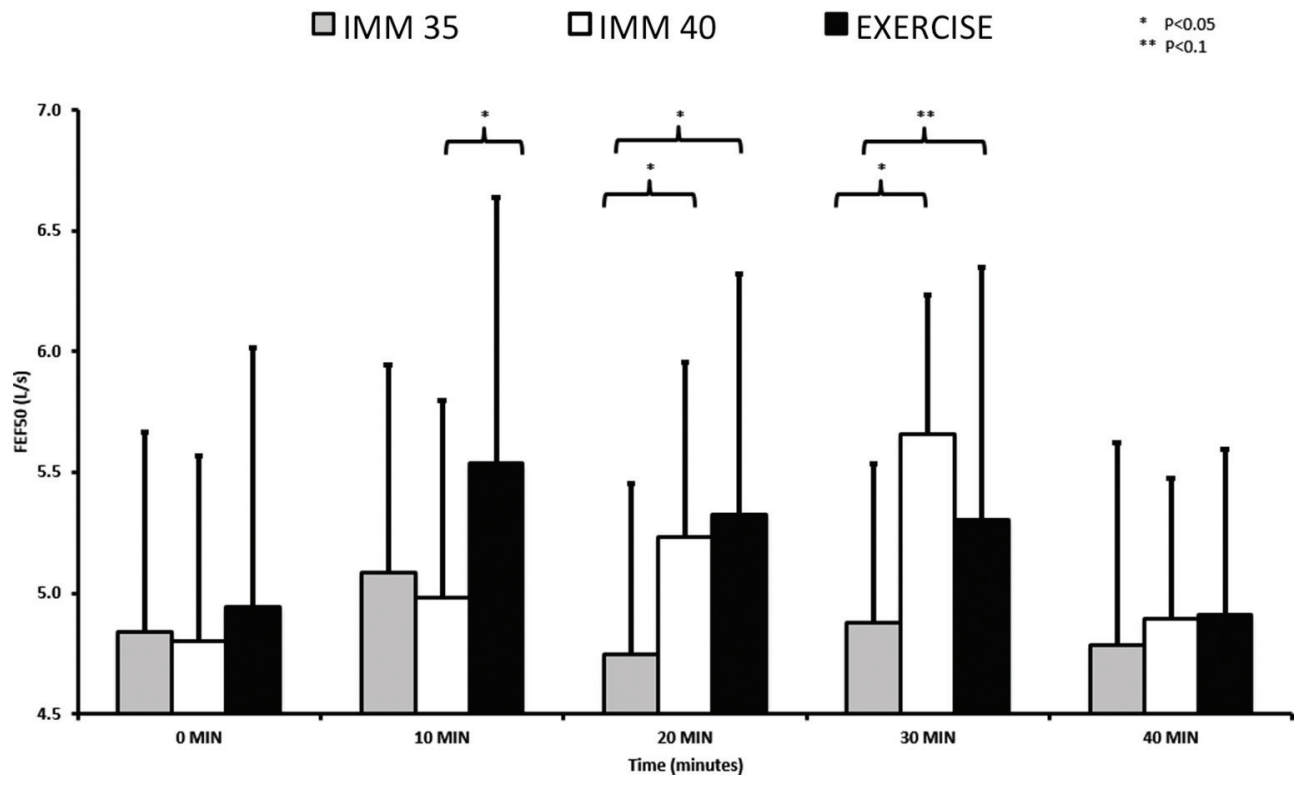

Figure 4 Mean (SD) FEF50 (L/s) data for each condition over the experimental period. Conditions and significant differences as marked $(\mathrm{n}=9)$. FEF50, forced expiratory flow $50 \% \mathrm{FVC}$; IMM35, $35^{\circ} \mathrm{C}$ water immersion; IMM $40,40^{\circ} \mathrm{C}$ water immersion; EXERCISE, clothed exercise for 30 minutes. 


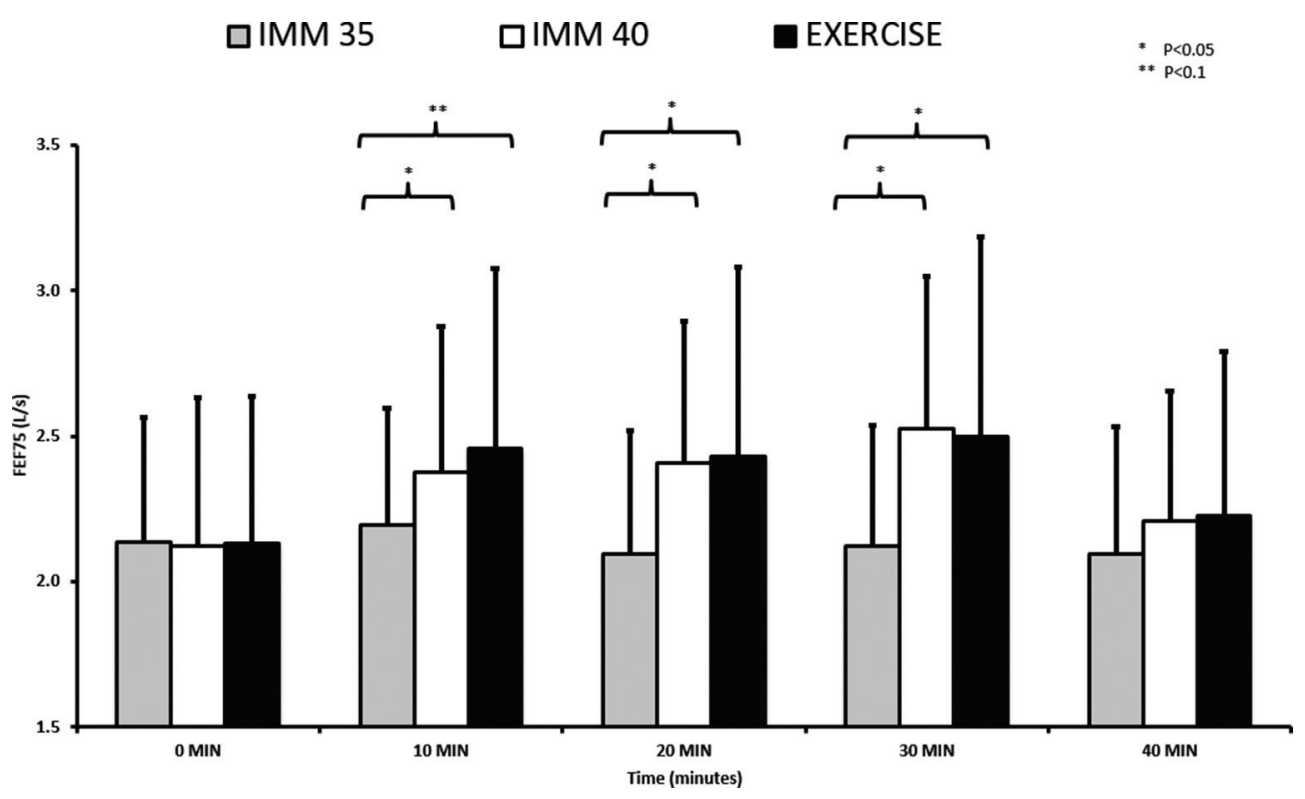

Figure 5 Mean (SD) FEF75 (L/s) data for each condition over the experimental period. Conditions and significant differences as marked $(n=9)$. FEF75, forced expiratory flow $75 \% \mathrm{FVC}$; IMM35, $35^{\circ} \mathrm{C}$ water immersion; IMM $40,40^{\circ} \mathrm{C}$ water immersion, EXERCISE, clothed exercise for 30 minutes.

airways, it would be expected that FEF25-75, FEF25, FEF50 and FEF75 would be reduced, whereas in restrictive airway disorders these values may be normal or reduced. When investigating decrements in airway function occurring with exercise-induced bronchospasm both falls in $\mathrm{FEV}_{1}$ and FEF25-75 should be observed, ${ }^{24}$ reflecting changes in resistance to airway flow through these smaller airways. However, falls in FEF25-75 are not always observed with exerciseinduced bronchoconstriction (EIB), and a diagnosis of EIB requires a postexercise reduction in lung function ( $>10 \%$ fall in $\mathrm{FEV}_{1}$ at two consecutive time points).

Despite research into the influence of exercise on bronchodilatation, and on hyperthermia-induced hyperventilation, there is a paucity of studies examining the impact of raised body temperature per se on airway flow and resistance. The present study tested the hypothesis that an increase in deep body temperature would, independently of exercise, produce changes in pulmonary flow rates similar to those seen with exercise.

\section{METHODS}

The protocol was approved by the University of Portsmouth Biosciences Research Ethics Committee. All participants provided written informed consent.

On the basis of a power calculation (StatMate 2, GraphPad, Prism), nine healthy (as judged by the health history questionnaire) male participants (mean (SD): age 22 (3) years; height 177.7 (8.3) cm; mass $80.2(19.1) \mathrm{kg}$ ) were recruited. Participants had no history of respiratory illness and were non-smokers. Exclusion criteria included: illness in the 2 weeks prior to commencing the study; history of either heat illness, asthma or any other lung disorder as well as chest wall deformities (kyphosis, scoliosis, pectus excavatum). Participants were also excluded if they were unable to achieve a reliable baseline measure during the respiratory manoeuvre familiarisation session, or if their baseline spirometry showed values representative of a possible bronchoconstrictive pathology or if the FVC value during exercise fitted the criteria for exerciseinduced bronchospasm.

The study used a within-participant repeated measures cross-over design with each participant acting as their own control. Following familiarisation testing, the participants completed a total of three experimental conditions on separate days. These were: (1) clothed (details below) exercise for $30 \mathrm{~min}$ to increase deep body temperature (EXERC); (2) supine immersion to the clavicle in $40^{\circ} \mathrm{C}$ water for $30 \mathrm{~min}$ to increase deep body temperature passively (IMM40); (3) seated immersion to the clavicle in thermoneutral $\left(35^{\circ} \mathrm{C}\right)$ water to control for the effects of hydrostatic pressure on spirometry (IMM35). The order of the conditions was randomised using a Latin square. All conditions took place at the same time of day $( \pm 1$ hour $)$ to minimise circadian variation and were separated by at least 24 hours. Thirty minutes of exercise and immersion were employed as it takes this time in adults for significant increases in deep body temperature to occur.

Participants abstained from alcohol and caffeine consumption and were asked not to carry out strenuous exercise in the 24 hours prior to each visit to the laboratory. They were asked to consume a light meal 2 to 3 hours prior to each test and otherwise continue with their normal diet.

FVC was measured using a spirometer (ML3300 microlab spirometer, MK3, Micromedical, Kent, UK). Prior to the start of the measurement, the investigator 
Table 1 Mean (SD) thermal and spirometry data after 30 and 40 min of each experimental condition $(n=9)$

\begin{tabular}{|c|c|c|c|c|c|c|}
\hline \multirow[b]{2}{*}{ Variable } & \multicolumn{3}{|l|}{$30 \mathrm{~min}$} & \multicolumn{3}{|l|}{$40 \mathrm{~min}$} \\
\hline & IMM35 & IMM40 & EXERC & IMM35 & IMM40 & EXERC \\
\hline $\mathrm{T}_{\mathrm{re}}\left({ }^{\circ} \mathrm{C}\right)$ & $37.2(0.2)$ & $38.2(0.2)$ & $38.0(0.3)$ & $37.3(0.2)$ & $37.4(2.0)$ & $37.3(1.7)$ \\
\hline $\mathrm{T}_{\text {skin }}\left({ }^{\circ} \mathrm{C}\right)$ & $33.5(2.3)$ & $36.5(4.4)$ & $34.5(1.7)$ & $30.0(2.7)$ & $32.7(1.7)$ & $33.9(1.3)$ \\
\hline HR (beats/min) & 60 (19) & $97(24)$ & $130(34)$ & $67(18)$ & $79(27)$ & $82(26)$ \\
\hline FVC (L) & $5.3(0.8)$ & $5.3(0.8)$ & $5.3(0.9)$ & $5.3(0.8)$ & $5.3(0.8)$ & $5.3(0.7)$ \\
\hline $\mathrm{FEV}_{1}(\mathrm{~L})$ & $4.4(0.5)$ & $4.6(0.6)$ & $4.5(0.6)$ & $4.3(0.6)$ & $4.4(0.5)$ & $4.4(0.5)$ \\
\hline $\mathrm{FEV}_{1} / \mathrm{FVC}(\%)$ & $82.8(5.4)$ & $87.0(6.0)$ & $85.1(7.6)$ & $82.6(3.9)$ & $83.8(5.8)$ & $83.1(6.1)$ \\
\hline FEF25 (L/s) & $8.1(1.0)$ & $8.5(0.9)$ & $8.2(1.4)$ & $7.8(1.3)$ & $8.2(0.8)$ & $8.0(0.9)$ \\
\hline FEF50 (L/s) & $4.9(0.7)$ & $5.7(0.6)$ & $5.3(1.0)$ & $4.8(0.8)$ & $4.9(0.6)$ & $4.9(0.7)$ \\
\hline FEF75 (L/s) & $2.1(0.4)$ & $2.5(0.5)$ & $2.5(0.70$ & $2.1(0.4)$ & $2.2(0.5)$ & $2.2(0.6)$ \\
\hline
\end{tabular}

FVC, forced vital capacity; $\mathrm{FEV}_{1}$, forced expiratory volume in $1 \mathrm{~s}$; FEF, forced expiratory flow; $\mathrm{HR}$, heart rate; IMM35, $35^{\circ} \mathrm{C}$ water immersion; IMM40, 40 C water immersion; EXERC, exercise; $\mathrm{T}_{\text {re }}$ EXERC, rectal temperature at exercise; $\mathrm{T}_{\text {re }}$, rectal temperature; $\mathrm{T}_{\text {skin }}$, skin temperature.

demonstrated the technique required. The participant was seated on a stool (standardised position to that of the main trial), with a nose clip and inserted the mouthpiece securely. Up to five attempts were allowed during familiarisation testing to ensure the measure achieved stability $(<0.2 \mathrm{~L}$ variation) before the volunteer was removed from the study. During the experimental conditions one attempt was allowed. The spirometer subsequently calculated the $\mathrm{FVC}, \mathrm{FEV}_{1}$ and FEF outputs. All measurements satisfied criteria proposed by the American Thoracic Society. ${ }^{25}$

Rectal temperature was measured using a rectal thermistor self-inserted $15 \mathrm{~cm}$ beyond the anal sphincter (Grant Instruments (Cambridge), Shepreth, UK). Skin temperature was measured using skin thermistors (Grant Instruments (Cambridge), Shepreth, UK) secured by single pieces of adhesive tape (Tegaderm, 3M Healthcare, Berkshire, UK) to the biceps, chest, thigh and calf for the subsequent calculation of mean skin temperature. ${ }^{26}$ The participant also wore a heart rate monitor (Polar RS800, Team Polar, Warwick, UK) throughout each trial condition. The procedural details of each condition are given below.

\section{Active heat (EXERC)}

The participants wore a bathing costume, tracksuit trousers, t-shirt, long sleeve jumper, running trainers and socks, full finger gloves and a woollen hat. The clothing ensured a significant rise in rectal temperature during exercise. They exercised on a cycle ergometer (Monark Ergomedic 828E, Försäljning, Sweden) pedalling at a fixed cadence $(70 \mathrm{rpm})$ and at $70 \%$ of their age-predicted maximum heart rate. They exercised for a $9 \mathrm{~min}$ period and stopped exercising for $1 \mathrm{~min}$ to perform a respiratory manoeuvre using the spirometer before recommencing exercise. They completed this sequence three times, giving a total time of $30 \mathrm{~min}$. They then rested for a further $10 \mathrm{~min}$ before undertaking one final spirometry measurement at $40 \mathrm{~min}$. The measures were taken with the subject seated on the bike and their feet on the central frame of the bike, similar to the seated position on the stool.

\section{Passive heat (IMM40)}

The participants were seated on a stool next to a bath of water at $40^{\circ} \mathrm{C}$. After providing an initial set of respiratory measures, they entered the bath and lay supine with their head out of the water. The spirometry measurements were taken at the same times as in EXERC. To remove the confounding effect of hydrostatic squeeze, the participants were asked to carefully stand after 9 min of immersion, climb out of the bath and sit on the stool, adjacent to the bath; this took approximately $1 \mathrm{~min}$. They then gave a respiratory measurement and immediately re-entered the bath. They repeated this sequence three times giving a total of $30 \mathrm{~min}$. They then rested, in air, for a further $10 \mathrm{~min}$ before undertaking one final spirometry measurement at $40 \mathrm{~min}$.

\section{Thermoneutral immersion (IMM35)}

The same procedure as stated for IMM40 was followed. However, the water temperature was $35^{\circ} \mathrm{C}$, which is thermoneutral water temperature for a naked, immersed human.

Mean (SD) for each spirometry measure $\left(\mathrm{FEV}_{1}, \mathrm{FEV}_{1} /\right.$ FVC, FEF75, FEF50 and FEF25) and deep body temperature were calculated for each experimental condition at rest $(0 \mathrm{~min})$ and after $10,20,30$ and $40 \mathrm{~min}$ of each condition. The data were then tested for their normality of distribution using a Kolmogorov-Smirnov test. Data were compared using a repeated measures analysis of variance within participant across time and experimental condition. The Results section concentrates on 
condition and interaction effects. Assumptions of sphericity were checked using Mauchly's test. Where nonspherical data sets were evident, as indicated by $p<0.05$, a Greenhouse-Geisser adjustment was used. The presence of statistically significant effects was determined using a post hoc (least significant difference) pairwise comparisons procedure. For all statistical tests, the $\alpha$ level was set at 0.05. PASW Statistics V.18.0 was used for all statistical analysis.

\section{RESULTS}

$\mathrm{T}_{\text {re }}$ rose at a similar rate in both EXERC and IMM40 conditions, both contrasted with the IMM35 condition, in which $T_{\text {re }}$ remained relatively stable. $T_{\text {re }}$ was significantly higher in the EXERC and IMM40 conditions compared with IMM35 $(\mathrm{p}=0.001)$; $\mathrm{T}_{\mathrm{re}}$ did not differ in IMM40 and EXERC conditions until $30 \mathrm{~min}$ (figure 1).

$\mathrm{FEV}_{1}$ was significantly higher $(\mathrm{p}=0.007)$ in the IMM40 condition and neared significance $(p=0.068)$ in the exercise condition compared with IMM35. FEV was not significantly different between EXERC and IMM40 (figure 2).

$\mathrm{FEV}_{1} / \mathrm{FVC}$ was significantly higher $(\mathrm{p}=0.004)$ in the IMM40 condition compared with IMM35. The difference between the EXERC condition compared with IMM35 did not reach statistical significance $(p=0.097)$. $\mathrm{FEV}_{1} / \mathrm{FVC}$ was not significantly different between EXERC and IMM40 (figure 3).

FEF25 did not show significant differences between conditions.

FEF50 did not reach significant differences between conditions $(p=0.075)$. The data suggested that, as the $\mathrm{T}_{\mathrm{re}}$ increased up to $30 \mathrm{~min}$ (the point near to which $\mathrm{T}_{\mathrm{re}}$ was highest), the airways dilated as the magnitude of the differences between IMM35 and IMM40 and IMM35 and EXERC became greater; differences between IMM40 and EXERC were only evident after $10 \mathrm{~min}$ and there were no differences between any of the conditions after $40 \mathrm{~min}$ (figure 4).

FEF75 changes approached statistical significant differences across condition $(p=0.054)$ but there were significant interaction effects that were in a similar direction as the FEF50 data $(\mathrm{p}=0.002)$ (figure 5).

The corresponding thermal and spirometry data for the 30 and $40 \mathrm{~min}$ time points, when the differences between conditions were greatest in the significant variables, are given in table 1 .

\section{DISCUSSION}

In this study, corresponding increases in deep body temperature were successfully induced with, and without, exercise. The results indicate a bronchodilatory response in the EXERC and IMM40 conditions, but not in the IMM35 condition. Therefore, the hypothesis that increased deep body temperature could, without exercise, influence lung function in a similar way to that seen with exercise, is accepted. To our knowledge, this is the first study to demonstrate an independent influence of temperature on respiratory flow rates, with temperature changes equivalent to those seen with exercise.

The $\mathrm{FEV}_{1}$ data showed significant changes between IMM40 and IMM35 $(\mathrm{p}=0.007)$ and approached statistically significant differences between EXERC and IMM35 $(p=0.068)$. This was a pattern that was also true for the $\mathrm{FEV}_{1} / \mathrm{FVC}$ data. A reason for the lack of a stronger statistical difference between the EXERC and IMM35 condition could be because $\mathrm{FEV}_{1}$ is, in part, a measure of the larger airways, and immediately following exercise, it is more difficult to make a maximal effort. A similar result has been reported in a healthy population, ${ }^{27}$ with a significant increase in the diameter of the smaller airways but no change in $\mathrm{FEV}_{1}$. In a population with asthma, ${ }^{28}$ an increase in the smaller airway diameter was observed with no increase in $\mathrm{FEV}_{1}$. In both studies, the influence of deep body temperature was not considered. Future studies should consider the use of non-volitional measures of airway calibre such as impulse oscillometry.

Significant interaction effects were found in the FEF50 and FEF75 (figures 4 and 5), with the primary differences evident between the conditions that raised deep body temperature (IMM40 and EXERC) and IMM35. These data support the suggestion that an increase in deep body temperature, whether through passive or active means, has a bronchodilatory effect on the small airways.

Research has shown that an alteration in body temperature influences ventilation and respiratory frequency ${ }^{18}$ as well as lung volumes. ${ }^{17}$ Ventilation is controlled by numerous factors, including: output from central command, input from central or peripheral chemoreceptors and input from muscle mechanoreceptors and metaboreceptors via group III and IV afferents, all of which are influenced by body temperature changes. Local temperature could have had an effect on the mechanical properties of the muscle and connective tissues and thereby respiratory function. Additionally, heat produced by passive or active means (eg, IMM40 or EXERC) could activate a mediator, such as the small heat shock protein HSP20 or E-type prostaglandins, that acts on smooth muscle and bronchial muscle tone. Also, this tone is controlled by the vagus by a reflex that may itself be temperature dependent. ${ }^{29}$ Milanese $e t a l^{30}$ reported that increased exercise intensity increased bronchodilation; they concluded that this was due to increased compliance of smooth muscle, the current study may suggest that it is the metabolic heat generated that, at least in part, causes the increase in compliance. It is also worth noting that while studies that last 5 min may be long enough to achieve metabolic steady state, they will not achieve a thermal steady state; due to thermal inertia this may take at least $30 \mathrm{~min}$. If increased deep body temperature is contributing to the changes seen in pulmonary resistance with exercise, this might explain why studies 
using shorter exercise periods have often failed to report changes, or have only reported them at higher workloads when body temperatures change faster. ${ }^{11} 31$

The FEF50 and FEF75 results at the $40 \mathrm{~min}$ time point may indicate that temperature is not the only variable affecting the airway flow as, even though $\mathrm{T}_{\mathrm{re}}$ remained elevated (and initially continued to rise in both EXERC and IMM40), FEF50 and FEF75 fell. Further research will help elucidate this finding as well as further determine the relative contribution of temperature and other factors in the bronchodilatation seen with exercise.

The limitations associated with this study included the indirect measurement of lung function and the use of otherwise healthy individuals. Further research, including with individuals with respiratory dysfunction (eg, asthma) and raised body temperate (eg, fever) should be considered.

It is concluded that a passive increase in body temperature appears to cause changes in lung function similar to the bronchodilation seen during exercise during which deep body temperature increases by a corresponding amount. These findings suggest that some of the bronchodilation seen with exercise is due, independently, to an increase in body temperature. This influence of body temperature has implications for experimental design and the interpretation of lung function data from tests where body temperature has been increased by exercise or other conditions.

Acknowledgements We gratefully acknowledge the participants who consented to be part of the study, Dr Mitch Lomax and other staff of the Extreme Environments Laboratory and Physiotherapy Department and HMS Nelson for their help and support during the project. In memoriam: Dr Mark 'Buster' Harries (Respiratory Consultant, Northwick Park Hospital)

Contributors MJT contributed to the conception, protocol production, data analysis and manuscript production. PK and MJB contributed to the protocol production, data collection and analysis, and manuscript production. DRdS contributed to the protocol production, data analysis and manuscript production.

Funding This project was funded by the University of Portsmouth.

Competing interests None declared.

Ethics approval University of Portsmouth Science Faculty Research Ethics Committee.

Provenance and peer review Not commissioned; externally peer reviewed.

Open Access This is an Open Access article distributed in accordance with the Creative Commons Attribution Non Commercial (CC BY-NC 4.0) license, which permits others to distribute, remix, adapt, build upon this work noncommercially, and license their derivative works on different terms, provided the original work is properly cited and the use is non-commercial. See: http:// creativecommons.org/licenses/by-nc/4.0/

(c) Article author(s) (or their employer(s) unless otherwise stated in the text of the article) 2017. All rights reserved. No commercial use is permitted unless otherwise expressly granted.

\section{REFERENCES}

1. Snyder EM, Beck KC, Dietz NM, et al. Influence of beta2-adrenergic receptor genotype on airway function during exercise in healthy adults. Chest 2006;129:762-70.
2. Mead J, Whittenberger JL. Physical properties of human lungs measured during spontaneous respiration. J Appl Physiol 1953;5:779-96.

3. Freedman S, Lane R, Gillett MK, et al. Abolition of methacholine induced bronchoconstriction by the hyperventilation of exercise or volition. Thorax 1988;43:631-6.

4. Beck KC, Hyatt RE, Mpougas P, et al. Evaluation of pulmonary resistance and maximal expiratory flow measurements during exercise in humans. J Appl Physiol 1999;86:1388-95.

5. Warren JB, Dalton N. A comparison of the bronchodilator and vasopressor effects of exercise levels of adrenaline in man. Clin Sci 1983;64:475-9.

6. Grossman A, Bouloux P, Price $\mathrm{P}$, et al. The role of opioid peptides in the hormonal responses to acute exercise in man. Clin Sci 1984;67:483-91.

7. Todaro A. Exercise-induced bronchodilatation in asthmatic Athletes. J Sports Med Phys Fitness 1996;36:60-6.

8. Clark AL, Galloway S, MacFarlane N, et al. Catecholamines contribute to exertional dyspnoea and to the ventilatory response to exercise in normal humans. Eur Heart $J$ 1997;18:1829-33.

9. Mansfield L, McDonnell J, Morgan W, et al. Airway response in asthmatic children during and after exercise. Respiration 1979;38:135-43.

10. Gelb AF, Tashkin DP, Epstein JD, et al. Exercise-induced bronchodilation in asthma. Chest 1985;87:196-201.

11. Freedman S. Exercise as a bronchodilator. Clin Sci 1992;83:383-9.

12. Suman OE, Beck KC, Babcock MA, et al. Airway obstruction during exercise and isocapnic hyperventilation in asthmatic subjects. $J$ Appl Physiol 1999;87:1107-13.

13. Crimi E, Pellegrino R, Smeraldi A, et al. Exercise-induced bronchodilation in natural and induced asthma: effects on ventilatory response and performance. J Appl Physiol 2002;92:2353-60.

14. Sargeant AJ. Effect of muscle temperature on leg extension force and short-term power output in humans. Eur J Appl Physiol Occup Physiol 1987;56:693-8.

15. Choukroun ML, Kays C, Varene P. EMG study of respiratory muscles in humans immersed at different water temperatures. J Appl Physiol 1990;68:611-6.

16. Suman OE, Babcock MA, Pegelow DF, et al. Airway obstruction during exercise in asthma. Am J Respir Crit Care Med 1995;152:24-31.

17. Choukroun ML, Kays $C$, Varène $P$. Effects of water temperature on pulmonary volumes in immersed human subjects. Respir Physiol 1989;75:255-65.

18. Hayashi $\mathrm{K}$, Honda $\mathrm{Y}$, Ogawa $\mathrm{T}$, et al. Relationship between ventilatory response and body temperature during prolonged submaximal exercise. J Appl Physiol 2006;100:414-20.

19. Martin BJ, Morgan EJ, Zwillich CW, et al. Control of breathing during prolonged exercise. J Appl Physiol Respir Environ Exerc Physiol 1981;50:27-31.

20. Stubbing DG, Pengelly LD, Morse JL, et al. Pulmonary mechanics during exercise in normal males. J Appl Physiol Respir Environ Exerc Physiol 1980;49:505-10.

21. Pride NB. Tests of forced expiration and inspiration. Clin Chest Med 2001;22:599-622.

22. McNulty W, Usmani OS. Techniques of assessing small airways dysfunction. Eur Clin Respir J 2014;1:25898.

23. Morris JF. Spirometry in the evaluation of pulmonary function. West $J$ Med 1976;125:110-8.

24. Custovic A, Arifhodzic N, Robinson A, et al. Exercise testing revisited. The response to exercise in normal and atopic children. Chest 1994;105:1127-32.

25. Standardization of Spirometry, 1994 Update. American Thoracic Society. Am J Respir Crit Care Med 1995;152:1107-36.

26. Ramanathan NL. A new weighting system for mean surface temperature of the human body. J Appl Physiol 1964;19:531-3.

27. Pichon A, Roulaud M, Denjean A, et al. Airway tone during exercise in healthy subjects: effects of salbutamol and ipratropium bromide. Int J Sports Med 2005;26:321-6.

28. Beck KC, Offord KP, Scanlon PD. Bronchoconstriction occurring during exercise in asthmatic subjects. Am J Respir Crit Care Med 1994;149:352-7.

29. Ben-Dov I, Bar-Yishay E, Godfrey S. Refractory period after exercise-induced asthma unexplained by respiratory heat loss. Am Rev Respir Dis 1982;125:530-4.

30. Milanese M, Saporiti R, Bartolini S, et al. Bronchodilator effects of exercise hyperpnea and albuterol in mild-to-moderate asthma. $J$ Appl Physiol 2009;107:494-9.

31. Kagawa J, Kerr HD. Effects of brief graded exercise on specific airway conductance in normal subjects. $J$ Appl Physiol 1970;28:138-44. 